\title{
A stochastic exposure assessment model to estimate vanadium intake by beef cattle used as sentinels for the South African vanadium mining industry
}

\author{
B. Gummow ${ }^{\text {a,* }}$, W.F.A. Kirsten ${ }^{\text {b }}$, R.J. Gummow ${ }^{\text {c }}$, \\ J.A.P. Heesterbeek ${ }^{\mathrm{d}}$ \\ ${ }^{a}$ Faculty of Veterinary Science, University of Pretoria, Private Bag X04, Onderstepoort, \\ Gauteng 0110, South Africa \\ ${ }^{\mathrm{b}}$ Agricultural Research Council, Institute for Soil, Climate and Water, P. Bag X79, \\ Pretoria 0001, South Africa \\ ${ }^{\mathrm{c}}$ Tshwane University of Technology, Department of Chemistry and Physics, \\ Pretoria, South Africa \\ ${ }^{\mathrm{d}}$ Faculty of Veterinary Medicine, University of Utrecht, \\ Yalelaan 7,3584 CL Utrecht, Netherlands
}

Received 8 September 2004; received in revised form 4 May 2006; accepted 4 May 2006

\begin{abstract}
This paper presents an environmental exposure assessment model for estimating chronic intake of vanadium (a transition metal) by cattle farmed extensively in areas contaminated by vanadium pollutants. The exposure model differs from most other models in several ways: (1) it does not rely heavily on extrapolating information from the point source (e.g. stack height, exit velocity, exit diameter) to the point of exposure. (2) It incorporates the physiological constraints of the species exposed. (3) It takes into account oral as well as inhalation exposure. (4) It addresses terrain, by using measurements at the point of exposure. (5) It accounts for existing background concentrations of pollutants and pollutants from multiple sources. (6) It uses a stochastic process with distribution functions to account for variability in the data over time. Environmental inputs into the model included aerial fall-out sample vanadium $(n=566)$, unwashed grass sample vanadium $(n=342)$ and soluble soil sample vanadium $(n=342)$. Physiological cattle inputs were derived from two cohorts of Brahman-cross sentinel cattle $(n=30)$. The model provided an estimate of the chronic external exposure dose of vanadium for two separate groups of cattle grazing over a 5-year period
\end{abstract}

* Corresponding author. Tel.: +2712 5298257; fax: +2712 5298315.

E-mail address: bruce.gummow@up.ac.za (B. Gummow). 
(1999-2004) immediately adjacent (median dose $=2.14 \mathrm{mg}$ vanadium $/ \mathrm{kg}$ body weight $/$ day) and $2 \mathrm{~km}$ away (median dose $=1.07 \mathrm{mg} / \mathrm{kg} / \mathrm{day}$ ) from a South African vanadium-processing plant, respectively. The final output of the model is a distribution curve of the probable vanadium intake based on the variability within the inputs over the 5-year period of the study. The model is adaptable enough for application to other transition metals and species (including man), and could be used as an alternative to plume-dispersion modelling.

(C) 2006 Elsevier B.V. All rights reserved.

Keywords: Environmental epidemiology; Vanadium; Pollution; Cattle; Model; Transition metals and exposure assessment

\section{Introduction}

"In less than 100 years, vanadium has gone from being a rare and obscure metal to become one of strategic military importance and a pillar of modern technology. As scientific and technological developments expand its horizon, vanadium is clearly poised to become the element for the twenty-first century"-Nriagu (1998). With this in mind, vanadium can potentially have an important environmental impact- especially in countries like South Africa, China, Russia and the USA (the main producers of vanadium). About $17 \%$ of worldwide vanadium production from primary sources is recovered from the oil industry and the rest is mined from vanadiferous magnetite $\left(\mathrm{Fe}_{2} \mathrm{O}_{3}\right)$ (Hilliard, 1992). Vanadium is most often used by industry in the manufacturing of steel, where it is used as ferrovanadium (Reilly, 1991; Toxicological Profile for Vanadium, 1992).

Vanadium can be toxic; poisoning has long been an occupational-health risk within industry (Faulkner Hudson, 1964; Gummow et al., 2005). Various species of animals are susceptible to vanadium poisoning (Faulkner Hudson, 1964) and outbreaks have occurred in cattle (ter Heege, 1964; Unpublished archival records of the Onderstepoort Veterinary Institute (OVI), Private Bag X05, Onderstepoort, 0110, 1961/1962, 1975/1976; Frank et al., 1992; Gummow et al., 1994; Frank et al., 1996; McCrindle et al., 2001). The pathogenesis of chronic vanadium poisoning in cattle is complex but involves malabsorption and immunosuppression (Gummow et al., 1994; Gummow, 2005). The symptoms can be variable, but the disease usually manifests initially in calves 0-6 months old, which show emaciation, chronic diarrhoea, sub-mandibular oedema, pot-belly and in some cases, facial paralysis, rhinitis, conjunctivitis and recumbency followed by death (Faulkner Hudson, 1964; Puls, 1989; Gummow, 2005). Symptoms in humans are usually as a response to industrial exposure and involve irritation of the eyes and respiratory system in the form of conjunctivitis, bronchospasm, bronchitis and asthma-like symptoms. Other symptoms of vanadium poisoning in humans include weakness, nausea, vomiting, anorexia, tinnitus, headache, dizziness, green discolourisation of the tongue, palpitations, transient coronary insufficiency, bradycardia with extra systoles, dermatitis, anaemia, leucopoenia, leukocyte granulation and lowering of cholesterol levels (Faulkner Hudson, 1964; Friberg et al., 1979; Reilly, 1991). Recent studies in humans show correlations between vanadium levels in urine and serum and cognitive deficits, particularly visuospatial abilities and attention (Barth et al., 2002). 
The close proximity between vanadium mines and cattle farms place cattle at risk of exposure to vanadium. However, little work has been done on the effects of chronic exposure to vanadium pollutants in ruminants or other species, including man (Toxicological Profile for Vanadium, 1992).

Exposure assessment describes the biological pathway(s) necessary for exposure of animals and humans to the hazards identified and estimating the likelihood of those exposure(s) occurring (Murry et al., 2004). Several investigators have suggested that the failure to assess exposure accurately has reduced the effectiveness of epidemiological research (Clarkson et al., 1983; Heath, 1983) and is the Achilles heel of traditional epidemiology (Perera and Weinstein, 1982). Poor exposure assessment promotes misclassification among exposed and comparison cohorts (Aldrich et al., 1993) and can lead to incorrect conclusions. Little work has been done to produce accurate exposureassessment models for cattle exposed to transition-metal pollutants (those metals found between groups IIA and IIIA on the periodic table) over long periods of time.

\section{Materials and methods}

\subsection{Experimental design}

A cohort study was carried out using 30 Bos indicus cows of the same approximate mass. They were purchased in 1999 as pregnant heifers and randomly divided by lottery into two groups: a high-exposure (HE) group of 10 and a low-exposure (LE) group of 20 cattle. The HE group was farmed in an area immediately adjacent to the mine where high background concentrations of vanadium were thought to occur (Fig. 1). The LE group was farmed approximately $2-3 \mathrm{~km}$ from the first group in an area thought to have much lower background vanadium concentrations (D. Stein, Environmental Officer, L. Ford, Technical Director and Engineer, personal communication, 1999). Both groups were farmed as an extensive beef cattle enterprise with a twenty percent annual replacement rate. The herd size was limited by the amount of available grazing and a stocking density of approximately 1 animal per 5 ha was used as a guideline. Pastures comprised portions of veld fenced off into camps (Fig. 1). This density on the unimproved veld vegetation assured uniform grazing of the palatable plants across the entire area within each camp.

\subsection{Observations and analytical procedures}

The farm was visited by at least one veterinary co-workers once every 3 months, to monitor the health status of the herd, collect samples and bring records up to date. A record system was kept by the Department of Production Animal Studies at the Faculty of Veterinary Science, University of Pretoria, for analyses purposes.

A weather-monitoring station was placed on the mine's property to measure wind direction, wind speed, ambient temperature, humidity and rainfall.

Nine deposit-samplers were placed in the LE pastures and six deposit-samplers in the HE pastures to capture airborne particulate matter (Fig. 1). A total of 566 aerial fall-out samples were collected between 1999 and 2004. Soil and grass samples were collected 


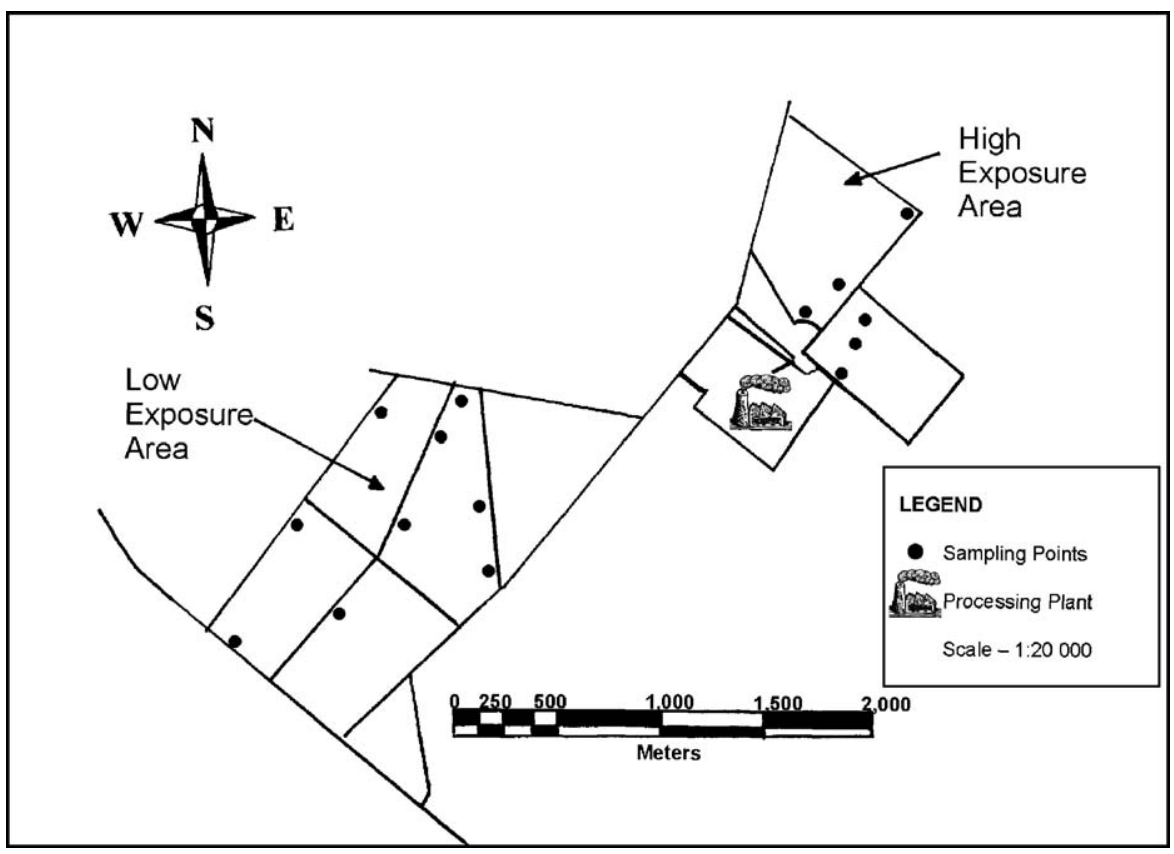

Fig. 1. Map of the area where the trial took place in South Africa during 1999-2004, showing the vanadium processing plant in relation to the LE and HE pastures and the points where samples were routinely collected.

once every 3-4 months at the same points as the deposit-samplers. A variety of palatable grass species were sampled within a radius of $50 \mathrm{~m}$ of each sampling point. The same approximate mass $(500 \mathrm{~g})$ of grass was collected each time. A total of 342 grass samples and 342 soil samples were collected over the 5-year period. At the same time, water samples $(n=62)$ were taken from the drinking troughs (the water itself came from the town council) and biological samples were taken from cattle (Gummow et al., 2006). The samples were analysed by the Institute of Soil, Climate and Water, Pretoria, South Africa, for concentrations of vanadium, using standard internationally accepted methods and quality-control procedures (USEPA Standard Methods, 1986, 1996; Handbook of Standard Soil Testing Methods for Advisory Purposes, 1990). The detection limit for vanadium using the EPA 3052 method was $0.052 \mathrm{mg} / \mathrm{kg}$.

\subsection{Exposure assessment}

Exposure assessment was carried out using stochastic simulation models that incorporated distribution functions defined by the input data and Latin-Hypercube sampling. The objective of the models was to simulate the amount of vanadium that cattle would have taken in during the project. The following is a description of a generic model that pools all the data for the duration of the trial. To reduce variance and to allow the exposure data to be correlated to the biomarker data, the data were also stratified into seasonal wet (October-February) and dry (March-September) periods for 1999/2000, 
2001/2002 and 2003/2004 and a separate model created for each of these strata. We decided not to stratify the periods any further because of the relatively small number of sampling points used for fall out and because, during certain periods of the trial, data from certain points could not be collected because of changes in mining operations, veld fires or staff problems.

The generic model was divided into three segments. The first segment comprised collation of the exposure data that had been recorded during the duration of the trial. This data comprised the aerial fall-out data, the grass concentrations of vanadium, soil concentrations of vanadium, background feed concentrations of vanadium and background water concentrations of vanadium over the duration of the trial (referred to below as exposure inputs). As explained above, the data were pooled for each year of the study into a wet season (October-February) and a dry season (March-September) based on meteorological data that was collected on site. This provided the first input into the model and each exposure input for that period was defined using a truncated lognormal distribution function generated by Bestfit version 4.5 (Palisade Corporation). The lognormal distribution function was consistently within the top-ranking distribution functions that Bestfit fitted to the data and is commonly used for environmental data. The function was truncated with a lower bound of zero to prevent the generation of negative values, which would be implausible, and an upper bound dependent on what was regarded as an unrealistic maximum for that exposure input. So the maximum aerial fall out was truncated at $100,000 \mu \mathrm{g} / \mathrm{m}^{2} /$ day, unwashed grass vanadium at $1000 \mathrm{mg} / \mathrm{kg} / \mathrm{day}$ and soluble (EDTA) soil vanadium concentrations at $50 \mathrm{mg} / \mathrm{kg} /$ day. This generated a distribution function for possible concentrations of vanadium representative of each exposure input. For the purpose of the generic model, a uniform distribution function was then used to combine the seasonal data over the years into a single distribution function representing the possible vanadium concentrations over the entire period of the trial for grass, soil, water and air, respectively. The resultant outputs of this segment of the model were therefore distribution functions that represented concentrations of vanadium in unwashed grass (mg/kg) (Fig. 3), concentrations of soluble vanadium in soil (mg/kg) (Fig. 4), aerial fall out $\left(\mu \mathrm{g} / \mathrm{m}^{2} /\right.$ day) (Fig. 5) and concentrations of vanadium in water sources used by the cattle $(\mu \mathrm{g} / \mathrm{l})$ in each exposure area over the entire period of the trial. The structure of the model was designed to allow examination of vanadium concentrations for a particular year, season or period, to examine trends related to the consequence assessment, but these results are discussed elsewhere (Gummow, 2005; Gummow et al., 2006).

The second segment of the model involved modelling the physiological intake parameters for cattle (Table 1). These were divided into vanadium that would be ingested orally through the intake of feed, water and soil, and vanadium that would be inhaled. Percutaneous absorption was not considered to be a route of intake for vanadium and thus was not included in the model. This assumption was made because of the relatively small amount of vanadium that is known to be absorbed across the gastro-intestinal barrier of monogastric animals (Friberg et al., 1979); bovine skin by comparison, having a smaller surface area and being much thicker, is likely to be an even poorer route of absorption. Similarly, while background concentrations of vanadium were monitored in the commercial winter supplementary licks and lucerne that cattle received, the small concentrations and short period of ingestion (2-3 months per year) of the lick and lucerne 
Table 1

Model for estimating the intake of environmental vanadium by two groups of South African cattle between 1999 and 2004

\begin{tabular}{|c|c|c|c|}
\hline & $\begin{array}{l}\text { High-exposure } \\
\text { group }\end{array}$ & $\begin{array}{l}\text { Low-exposure } \\
\text { group }\end{array}$ & $\begin{array}{l}\text { Comment/distribution } \\
\text { function }\end{array}$ \\
\hline \multicolumn{4}{|l|}{ Oral intake } \\
\hline \multicolumn{4}{|l|}{ Grass (veld) diet } \\
\hline $\begin{array}{l}\text { Group body weight standard } \\
\text { deviation }(\mathrm{kg})\end{array}$ & 74 & 67 & From trial data \\
\hline Group body weight mean $(\mathrm{kg})$ & 472 & 442 & From trial data \\
\hline Body weight function & 471 & 442 & $\begin{array}{l}\text { RiskNormal, } \\
\text { RiskTruncate }(250,650)\end{array}$ \\
\hline$\%$ of body weight & 0.02 & 0.02 & (RiskUniform $(0.01,0.025))$ \\
\hline Grass dry-matter-intake (kg/day) & 8.2 & 7.74 & \\
\hline Vanadium in grass $(\mathrm{mg} / \mathrm{kg})$ & 148.00 & 68.00 & From unwashed grass model \\
\hline Vanadium ingested in grass (mg/day) & $1.22 \times 10^{3}$ & 526.00 & \\
\hline \multicolumn{4}{|l|}{ Water } \\
\hline $\begin{array}{l}\text { Volume of water ingested } \\
\qquad(\text { cows }(>24 \text { months }))(1 / \text { day })\end{array}$ & 34.95 & 32.84 & $\begin{array}{l}\mathrm{WI}=0.075+4.234 \times \\
\mathrm{DMI}+-1.15\end{array}$ \\
\hline Vanadium in water $(\mu \mathrm{g} / \mathrm{l})$ & 23.50 & 21.00 & \\
\hline Vanadium ingested in water ( $\mu \mathrm{g} /$ day $)$ & 821.37 & 689.66 & \\
\hline Vanadium ingested in water (mg/day) & 0.82 & 0.69 & \\
\hline \multicolumn{4}{|l|}{ Soil ingested } \\
\hline $1-18 \%$ of DMI & 0.10 & 0.10 & RiskUniform $(0.01,0.18)$ \\
\hline Amount of soil ingested (kg/day) & 0.78 & 0.74 & \\
\hline Soluble vanadium in soil (mg/kg) & 6.00 & 5.00 & From EDTA soil model \\
\hline $\begin{array}{l}\text { Vanadium ingested with soil } \\
\text { intake (mg/day) }\end{array}$ & 4.70 & 3.68 & \\
\hline $\begin{array}{l}\text { Vanadium ingested per cow per } \\
\text { day (mg/day) }\end{array}$ & $1.22 \times 10^{3}$ & 531 & \\
\hline \multicolumn{4}{|l|}{ Inhalation intake } \\
\hline $\begin{array}{l}\text { Vanadium concentration in air } \\
\left(\mu \mathrm{g} / \mathrm{m}^{2} / \text { day }\right)\end{array}$ & $6.97 \times 10^{3}$ & $1.66 \times 10^{3}$ & From aerial fall-out model \\
\hline Diameter of collector $(\mathrm{m})$ & 0.19 & 0.19 & \\
\hline Radius of collector $(\mathrm{m})$ & 0.09 & 0.09 & \\
\hline $\begin{array}{l}\text { Gravitational acceleration constant } \\
\quad[\mathrm{g}]\left(\mathrm{m} / \mathrm{s}^{2}\right)\end{array}$ & 9.80 & 9.80 & \\
\hline Pi constant & 3.14 & 3.14 & \\
\hline Radius of vanadium particles $[r](\mathrm{m})$ & $5.00 \times 10^{-5}$ & $5.00 \times 10^{-5}$ & $\begin{array}{l}\text { RiskUniform }\left(4 \times 10^{-6},\right. \\
\left.6 \times 10^{-6}\right)\end{array}$ \\
\hline Density of $\mathrm{V}_{2} \mathrm{O}_{5}[\rho](\mathrm{g} / \mathrm{ml})$ & $3.36 \times 10^{3}$ & $3.36 \times 10^{3}$ & \\
\hline Density of the air $[\sigma]$ & 1.20 & 1.20 & $\mathrm{~g} / \mathrm{l}$ at $25 \mathrm{C}=\mathrm{kg} / \mathrm{m}^{3}$ \\
\hline Viscosity of the air $[\eta]$ (Pa s) & $1.80 \times 10^{-5}$ & $1.80 \times 10^{-5}$ & \\
\hline Vertical terminal velocity $\left(v_{\mathrm{t}}\right)(\mathrm{m} / \mathrm{s})$ & 1.01 & 1.01 & \\
\hline Volume of air sampled in $24 \mathrm{~h}\left(\mathrm{~m}^{3}\right)$ & $2.36 \times 10^{3}$ & $2.36 \times 10^{3}$ & \\
\hline $\begin{array}{l}\text { Vanadium concentration in } \mathrm{m}^{3} \text { air } \\
\left(\mu \mathrm{g} / \mathrm{m}^{3} / \text { day }\right)\end{array}$ & 2.96 & 0.71 & \\
\hline $\begin{array}{l}\text { Vanadium concentration in litre } \\
\text { air }(\mu \mathrm{g} / \mathrm{l})\end{array}$ & $3.00 \times 10^{-3}$ & $7.00 \times 10^{-4}$ & \\
\hline Respiratory rate & 30.00 & 30.00 & $\begin{array}{l}\text { RiskNormal }(30,1.8, \\
\text { RiskTruncate }(15,60))\end{array}$ \\
\hline
\end{tabular}


Table 1 (Continued)

\begin{tabular}{lccl}
\hline & $\begin{array}{l}\text { High-exposure } \\
\text { group }\end{array}$ & $\begin{array}{l}\text { Low-exposure } \\
\text { group }\end{array}$ & $\begin{array}{l}\text { Comment/distribution } \\
\text { function }\end{array}$ \\
\hline Tidal volume & 3.50 & 3.50 & RiskNormal(3.5,0.4) \\
Respiratory rate per day & $4.32 \times 10^{4}$ & $4.32 \times 10^{4}$ & Over $24 \mathrm{~h}$ \\
$\quad \begin{array}{l}\text { Respiratory volume = Resp. } \\
\text { freq. } \times \text { tidal volume (1/day) }\end{array}$ & $1.30 \times 106$ & $1.30 \times 10^{6}$ & \\
Vanadium inhaled per cow & & & \\
$\quad$ per day (mg/day) & $\mathbf{3 . 8 3}$ & $\mathbf{0 . 9 1}$ & \\
$\quad$ & & & \\
Total intake of vanadium per cow & $\mathbf{1 . 2 3} \times \mathbf{1 0}^{3}$ & $\mathbf{5 3 2 . 0 0}$ & \\
$\quad$ per day (mg/day) & & & Output (mg/kg/day) \\
$\quad$ Dose of vanadium per kg per day & & & \\
$\quad$ Minimum & 0.05 & 0.01 & \\
5 percentile & 0.56 & 0.33 & \\
50 percentile & 2.14 & 1.07 & \\
95 percentile & 6.58 & 2.73 & \\
Maximum & 23.96 & 12.72 & \\
\hline
\end{tabular}

resulted in a negligible amount of extra vanadium per day; so this source of intake was also not included in the generic model.

The intake of veld grass for adult cattle ( $>24$ months) is reported to be $1-2.5 \%$ of their body mass (Smith, 1990). This range of possible intakes was simulated using a Uniform $(0.01,0.025)$ distribution function. This function was multiplied by a Normal distribution function based on the mean mass and standard deviation for each group of cattle ( $n$ samples $=438$ HE-group samples; $n$ samples $=672$ LE-group samples). The result was a distribution function for the mass of grass ingested per day per adult cow (dry-matter intake, DMI). This was multiplied by the concentrations of vanadium in unwashed grass for the respective HE and LE pastures, that was simulated as described above, to give a distribution for the amount of vanadium ingested by eating grass per cow per day.

The volume of water ingested per day by adult cattle was calculated using the equation $0.075+4.234 \times$ DMI (La Manna et al., 1999). The DMI used in the equation was calculated as described above for each group. The volume of water ingested per day was then multiplied by the concentration of vanadium present in the water of each group as described above, to give a distribution for the amount of vanadium imbibed per cow per day.

The amount of soil ingested per day during the course of grazing is estimated to be between 1 and 18\% of DMI (Healy, 1968, 1970; Thornton and Abrahams, 1981). This distribution of potential values was again modelled using a Uniform $(0.01,0.18)$ distribution function and multiplied by the DMI value calculated above to give a distribution for the amount of soil ingested per cow per day. This was multiplied by the concentration of soluble vanadium (designated as EDTA from its method of determination) in the soil as described above to give a distribution for the amount of vanadium ingested by soil intake per cow per day. Total oral intake of vanadium was then the sum of the grass, water and soil intakes per cow per day. 
The mean ground air speed over each relevant time period was calculated using data captured by the weather station set up on the mine for this purpose. The wind speeds were stratified according to wind directions, and the mean wind speed calculated for winds blowing in the direction of the HE and LE pastures. To take into account the difference in predominant wind direction, the mean wind speeds were weighted by the frequency that the wind blew in the direction of the HE and LE pastures, respectively (Fig. 2).

To estimate the amount of vanadium inhaled, the vertical terminal velocity of a $\mathrm{V}_{2} \mathrm{O}_{5}$ particle was calculated according to the formula:

$$
v_{\mathrm{t}}=\frac{2 r_{\mathrm{v}}^{2}(\rho-\sigma) g}{9 \eta}
$$

where $r_{\mathrm{v}}$, radius of vanadium particle; $\rho$, density of $\mathrm{V}_{2} \mathrm{O}_{5} ; \sigma$, density of air; $g$, gravitational acceleration and $\eta$, viscosity of air (Whelan and Hodgson, 1979). Inputs for the formula were obtained from the CRC Handbook of Chemistry and Physics (1977), with the exception of the radius of vanadium particles, which was derived from expert opinion (obtained from the mine's engineers). The radius was therefore modelled as a Uniform distribution function representing the range 30-60 $\mu \mathrm{m}$.

The time for particles to move horizontally over the fall-out bucket $(\Delta t)$ was calculated by dividing the diameter of the fall-out bucket $(\phi)$ by the weighted wind speed (ws).



- - Wind Direction $(\%$ of year $) \quad$ - Wind Speed $(\mathrm{km} / \mathrm{h})$

Fig. 2. Rosette showing wind direction and wind speed relative to the South African vanadium processing plant for the period 1999-2004. 
To determine the height of the column of air that contributed to the vanadium deposited in the bucket, this time was then multiplied by the vertical terminal velocity $\left(v_{\mathrm{t}}\right)$ to give the change in vertical distance $\left(\Delta s_{\text {vert }}\right)$ of particles in this time. The volume of air sampled in time delta $t$ was then calculated using the formula

$$
V_{\mathrm{air}}=\Pi r^{2} \times \Delta s_{\mathrm{vert}}=\frac{\Pi r^{2} \times v_{\mathrm{t}} \times \phi}{\mathrm{ws}}
$$

where $r$ is the radius of the fall out buckets. The volume of air sampled in a $24 \mathrm{~h}$ period could then be calculated as: $V_{\text {air }} / \Delta t \times 24 \mathrm{~h} \times 3600 \mathrm{~s} / \mathrm{h}=\Pi r^{2} \times v_{\mathrm{t}} \times 24 \mathrm{~h} \times 3600 \mathrm{~s} / \mathrm{h}$. Hence the volume of air sampled in $24 \mathrm{~h}$ is directly proportional to the fall-out surface area and vertical terminal velocity of the vanadium particles.

The fall-out concentration of vanadium was then divided by the volume of air $\left(V_{\text {air }}\right)$ to give the concentration of vanadium per $\mathrm{m}^{3}$ of air. This was converted to vanadium concentration per litre of air by dividing by 1000 . The respiratory rate per minute of an adult bovid was modelled using a Normal distribution function with a mean of 30 and standard deviation of 1.8, truncated at 15 and 60 (Svendsen and Carter, 1984; Reece, 1991). This was multiplied by $60 \times 24$ to give the 24 -h respiratory rate. The tidal volume was modelled using a Normal distribution function with a mean of 3.5 and a standard deviation of 0.4 (Svendsen and Carter, 1984). The daily respiratory volume could then be calculated by multiplying the tidal volume by the 24 -h respiratory rate. This was then multiplied by the vanadium concentration per litre of air to give an estimation of the amount of vanadium inhaled by an adult cow per day.

The output of the model was then the sum of the oral daily dose of vanadium and the daily inhalation dose of vanadium to give a distribution for the daily exposure dose for cattle in the HE pastures and LE pastures.

\subsection{Data analysis}

All the models were constructed in MS Excel version 2000 (Microsoft Corporation) and simulated using the Excel add in @Risk version 4.5 (Palisade Corporation). Each simulation was run using Latin Hypercube sampling with 100,000 iterations. The selection of distribution functions was done according to guidelines set out by Vose (2000) in conjunction with the software programme BestFit (Palisade Corporation). A hundred thousand iterations were run to obtain a smooth distribution curve and the number of iterations exceeded the minimum number required for stability and convergence.

\subsection{Credibility of model inputs}

Duplicate soil and grass samples were sent to independent accredited laboratories every 4-6 months to ensure that the methods of analysis remained accurate. Results were consistently examined for outliers and, when present, analysis of these samples was repeated. The grass results were also compared with the results of an independent survey carried out in 1998 by Strass Environmental Science \& Engineering (SESE) 
where grass samples were taken for the mine on a $50 \mathrm{~m} \times 50 \mathrm{~m}$ grid basis in the area of the HE pastures. The grass samples taken by SESE (1998) were washed prior to being analysed for vanadium and hence were compared to washed grass samples taken in this study.

An independent company was contracted by the mine to model atmospheric dispersion of air pollution (Burger and Watson, 2003). The model used for the dispersion simulation was a traditional steady state Gaussian plume-dispersion type model referred to as the Industrial Source Complex model (EPA, 1995a,b). This model was used to predict the monthly fall-out of vanadium for the period September 1999-July 2001 at the grid reference points used to measure aerial fall-out of vanadium for the trial. The predicted concentrations were compared to the fall-out values in this study in an attempt to test the validity of the aerial fall-out portion of the exposure assessment model.

\subsection{Sensitivity analysis}

A sensitivity analysis was performed on the output variables and their associated inputs using multivariate stepwise regression and rank-order correlation analysis. The input distributions were then ranked by their impacts on the output and the results were examined to verify that the relationship was reasonable.

\section{Results}

\subsection{Exposure assessment}

\subsubsection{Unwashed grass}

The predicted concentrations of vanadium in unwashed grass over the entire 5-year period (Fig. 3) show a clear difference in unwashed grass concentrations between the LE

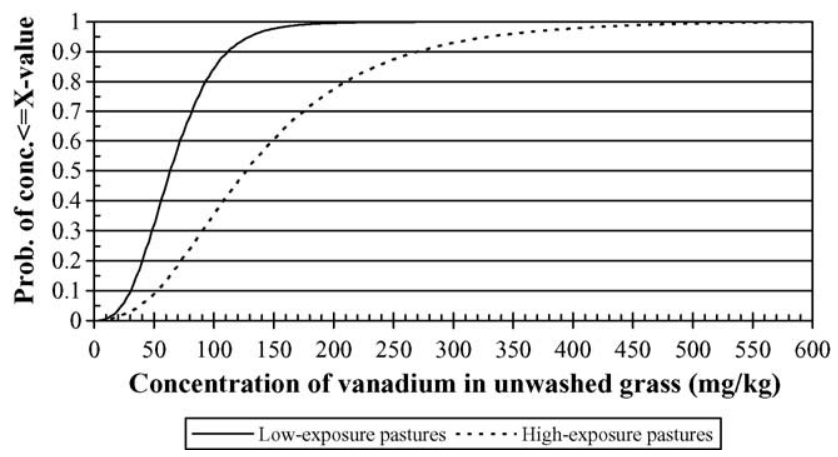

Fig. 3. Predicted concentration of vanadium in unwashed grass in two areas close to a South African vanadium mine for the period 1999-2004. 


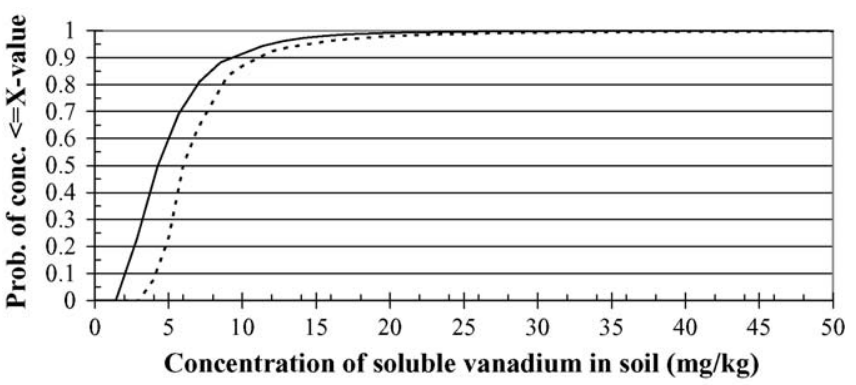

Low-exposure pastures $\cdots \cdot$... High-exposure pastures

Fig. 4. Predicted concentration of soluble vanadium in soil from two areas close to a South African vanadium mine for the period 1999-2004.

and HE pastures, with the magnitude of difference decreasing with a decrease in predicted vanadium concentration.

\subsubsection{Soil vanadium concentration (EDTA)}

The predicted soil concentrations of soluble vanadium (Fig. 4) show a fairly stable soluble vanadium soil profile with little difference between the pastures.

The total vanadium concentrations in the soil of the LE pastures (median $=622 \mathrm{mg} / \mathrm{kg}$ ) were consistently higher than those of the HE pastures (median $=392 \mathrm{mg} / \mathrm{kg}$ ), yet the soluble fractions reflected the inverse (0.8\% LE pastures and $1.5 \%$ HE pastures).

\subsubsection{Aerial fall out of vanadium}

There was more variation in the aerial fall-out for the HE pastures than the LE ones (Fig. 5). As with grass concentrations, the magnitude of difference between the LE and HE pastures increased with increasing concentrations. Nevertheless, the probability of extreme values even in the HE pastures was predicted to be quite small.

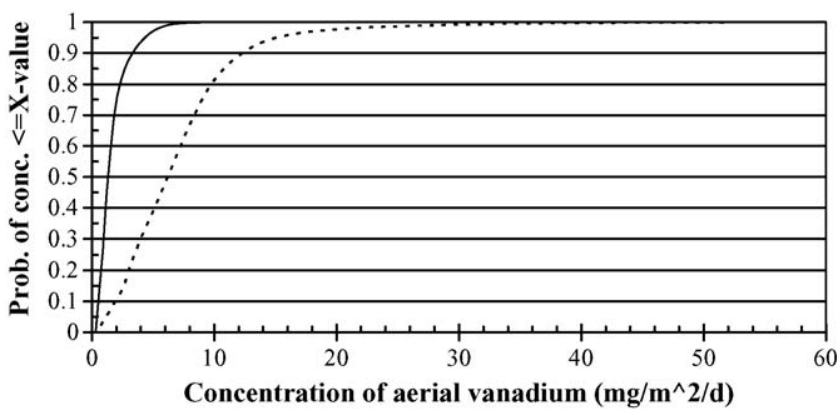

Low-exposure pastures $\cdots \cdots$ High-exposure pastures

Fig. 5. Predicted aerial fall-out of vanadium close to a South African vanadium mine for the period 1999-2004. 


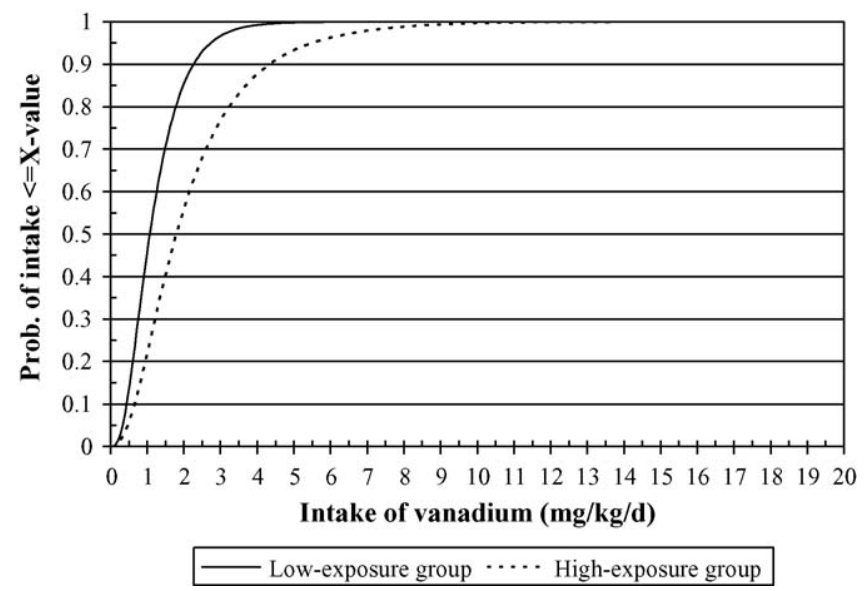

Fig. 6. Exposure dose ( $\mathrm{mg} / \mathrm{kg}$ body weight/day) of vanadium for adult South African cattle grazing near a vanadium mine between 1999 and 2004.

\subsubsection{Intake portion of model-exposure dose of vanadium}

See Table 1 and Fig. 6.

\subsection{Credibility of model inputs}

The washed-grass results $(n=37)$ of SESE (1998) were modelled using a Normal truncated distribution function, as used in the model, and compared to the output for the washed-grass results recorded in this trial (Table 2). The SESE results were lower but similar in magnitude to the results recorded in this trial. Quality control done by SESE (1998) on their own results $(n=6)$ also showed their results to be lower on average than those of the laboratory that tested the duplicate samples $(\bar{x}=159 \mathrm{mg} / \mathrm{kg}$ versus $174 \mathrm{mg} / \mathrm{kg}$, respectively).

We used a Gaussian plume-dispersion simulation model created for the mine by Burger and Watson (2003) to simulate fall out of $\mathrm{V}_{2} \mathrm{O}_{5}$ at the geographic coordinates used for collection of fall-out samples. Their model predicted median ambient concentrations of $\mathrm{V}_{2} \mathrm{O}_{5}$ for the period September 1999-July 2001 as $0.25 \mu \mathrm{g} / \mathrm{m}^{3}$ for the LE pastures and $2.74 \mu \mathrm{g} / \mathrm{m}^{3}$ for the $\mathrm{HE}$ pastures. Inputs into our intake model estimated ambient concentrations of $\mathrm{V}_{2} \mathrm{O}_{5}$ as 0.71 and $2.96 \mu \mathrm{g} / \mathrm{m}^{3}$ over the 5-year period of the trial for the LE and HE pastures, respectively. These values are thus similar to the plume-dispersion model predictions.

Table 2

Comparison of simulation results for washed grass samples taken near a South African vanadium mine between 1999 and 2004 and by an independent company (SESE) in 1998 (mg/kg)

\begin{tabular}{lcc}
\hline & $1999-2004$ results & 1998 SESE results \\
\hline Minimum & 0 & 0 \\
5 percentile & 26 & 10 \\
50 percentile & 137 & 84 \\
95 percentile & 263 & 177 \\
Maximum & 481 & 355 \\
\hline
\end{tabular}


Table 3

Sensitivity analysis results showing the ranking of the main input distributions by their impact on the 1999-2004 exposure dose output for each group of South African cattle

\begin{tabular}{llllll}
\hline Input variable & \multicolumn{2}{l}{ Low-exposure group } & & \multicolumn{2}{l}{ High-exposure group } \\
\cline { 2 - 3 } & $\begin{array}{l}\text { Least-square } \\
\text { regression }\end{array}$ & $\begin{array}{l}\text { Rank-order } \\
\text { correlation }\end{array}$ & & $\begin{array}{l}\text { Least-square } \\
\text { regression }\end{array}$ & $\begin{array}{l}\text { Rank-order } \\
\text { correlation }\end{array}$ \\
\hline Grass-dry season & 0.54 & & 0.51 & 0.70 & 0.67 \\
$\begin{array}{l}\text { Grass-wet season } \\
\text { \% of body weight used to }\end{array}$ & 0.55 & 0.56 & & 0.40 & 0.38 \\
$\begin{array}{l}\text { calculate DMI } \\
\text { Body weight }\end{array}$ & 0.24 & 0.58 & & 0.36 & 0.54 \\
\hline
\end{tabular}

\subsection{Sensitivity analysis}

Multivariable stepwise regression and rank-order correlations between the inputs and the predicted exposure dose produced the same impact ranking. As expected, grass vanadium concentrations had the greatest impact on the exposure-dose output for both the HE and LE groups (Table 3); dry seasons had more influence on the HE group exposure dose than wet seasons due to build up of dust on the grass during these periods. Changes in body weight and the related DMI were also found to have a noticeable effect on the predicted exposure dose. Changes in other inputs had relatively small effects on the predicted exposure dose. Because oral intake of grass was the primary source of vanadium for cattle, the model's behaviour makes biological sense.

\section{Discussion}

Our exposure-assessment model predicted a median intake dose of $2.14 \mathrm{mg}$ vanadium/ $\mathrm{kg}$ body weight/day for the HE animals over the 5 years of the study and $1.07 \mathrm{mg}$ vanadium $/ \mathrm{kg}$ body weight/day for the LE animals. The difference in exposure between the two groups reflects the difference in distance from the primary release sources of vanadium and the differences in wind direction and wind prevalence. The intake dose varied over the 5 years but, as shown in the output distribution function, is unlikely to have exceeded $23.96 \mathrm{mg} / \mathrm{kg} / \mathrm{day}$ in the HE group and $12.72 \mathrm{mg} / \mathrm{kg} / \mathrm{day}$ in the LE group, with an absolute minimum dose of $0.05 \mathrm{mg} / \mathrm{kg} /$ day and $0.01 \mathrm{mg} / \mathrm{kg} /$ day in the respective groups. In all previous field outbreaks of vanadium poisoning in cattle, the actual dose of vanadium never appears to have been quantified. What is normally reported are the high background concentrations of vanadium, which by inference were the cause of toxicity (Frank et al., 1992, 1996; Gummow et al., 1994; McCrindle et al., 2001). Even pollution-control guidelines normally break up exposure limits into compartments of air quality, water or "other", which usually refers to oral intake (WHO, 1987; Toxicological Profile for Vanadium, 1992). There are therefore no known previous studies reflecting a composite intake of vanadium by several intake routes over a long period of time. Hence the result of this study is important in providing methodology for establishing guidelines for a noobserved-adverse-effect-level (NOAEL) for cattle farmed in areas of high background 
levels of vanadium, which include the vicinity of vanadium-producing industries. It is also important in providing the means for calculating time series exposure doses that are necessary before one can evaluate biomarkers for assessing vanadium exposure. It thus provides a useful platform for future studies.

Our model shows that by far the largest component of vanadium intake is from the grass ingested by the cattle ( $99 \%$ for the HE and LE pastures). That most of the vanadium intake came from the grass ingested by the cattle means that grazing animals will take in more vanadium than other animals and humans in close proximity to a source of vanadium pollution and should act as good sentinels of vanadium pollution. Most human-health environmental epidemiology and occupational-health studies focus on inhalation and do not account for other routes of intake (Scott et al., 2003a). These methods are therefore not applicable to grazing animals (Scott et al., 2003b) because the methods exclude the major route of intake found in this study. Scott et al. (2003a) in their paper debate the merits and weaknesses of various approaches to exposure assessment for point sources. They categorise these approaches into "simple" methods, which include application of mathematical decay functions (based on the assumption that exposure decreases as a function of increasing distance from a pollution source) and "complex" atmosphericplume-dispersion models, the most common being the Gaussian plume-dispersion models. The exposure model we put forward differs from most other approaches:

1. It does not rely heavily on extrapolating information from the point source (e.g. stack height, exit velocity, exit diameter) to the point of exposure.

2. It incorporates the physiological constraints of the species exposed.

3. It takes into account oral as well as inhalation exposure. This is important because the model accounts for intake from contaminated grazing, vegetables and crops grown in the area of pollution.

4. It partially addresses one of the most common weaknesses of most other models (insensitivity to terrain specifications), by using measurements at the point of exposure.

5. It accounts for existing background concentrations of pollutants and pollutants from other origins, while most other models assume exposure is derived solely from a few known sources.

6. It accounts for variability in the data over time, which is usually a problem with longterm studies.

One of the arguments put forward against "static deposition" or "area monitors" is the cost and availability. This aspect still needs to be looked at within the South African context before any firm conclusions can be drawn in this respect.

Published results show a NOAEL of $0.7 \mathrm{mg} \mathrm{V} \mathrm{V}_{5} / \mathrm{kg} /$ day in the drinking water of rats (Schroeder et al., 1970) and $0.54 \mathrm{mg} \mathrm{V}_{2} \mathrm{O}_{5} / \mathrm{kg} /$ day in the drinking water of mice (Schroeder and Mitchener, 1975) exposed for 2.5 years. Schroeder and Balassa (1967) reported a NOAEL of $4.1 \mathrm{mg} \mathrm{V}_{2} \mathrm{O}_{5} / \mathrm{kg} /$ day in the feed of mice exposed for 2 years. The values we found for this study for oral intake of vanadium from the grazing were $2.14 \mathrm{mg} / \mathrm{kg} / \mathrm{day}$ for the HE group and $1.07 \mathrm{mg} / \mathrm{kg} /$ day for the LE group. This puts cattle in both groups on the threshold of developing adverse effects. In fact, we found that the calves in the HE group developed symptoms of vanadium poisoning while calves in the LE group did not 
(Gummow, 2005), thus putting the NOAEL for cattle somewhere between the LE and HE doses and in the same region as that of mice and rats (the only other species on which longterm studies have been carried out).

The vanadium determined in the unwashed grass samples consists of both vanadium dust deposited on the surface of the grass from airborne pollution and vanadium contained within the grass itself. Comparison of the vanadium levels in washed and unwashed grass from the HE pastures show that a high percentage $( \pm 92 \%)$ of the vanadium is actually contained within the grass itself. The median total vanadium grass levels found in this study in both the HE and LE pastures, 127 and $64 \mathrm{mg} / \mathrm{kg}$, respectively, were much higher than the recommended feedlot supplement of $0.57 \mathrm{mg} / \mathrm{kg}$ in a total ration (Fox, 1987) and the level of $1 \mathrm{mg} / \mathrm{kg}$ given as an average normal value for higher plants (Faulkner Hudson, 1964; Platonow and Abbey, 1968; Waters, 1977). Gummow et al. (1994) when examining grass vanadium concentrations around another vanadium smelter also found grass to have concentrations of vanadium $>10 \mathrm{ppm}$. The possibility that certain species of grass may accumulate or reflect soil concentrations of vanadium therefore needs to be investigated further.

Although the inhalation component of this exposure model accounts for $<1 \%$ of the intake, the predicted levels in the HE group $\left(2.96 \mu \mathrm{g} / \mathrm{m}^{3} /\right.$ day $)$ exceeded the WHO airquality guidelines for the time-weighted-average (TWA) for vanadium of $<1 \mu \mathrm{g} / \mathrm{m}^{3} /$ day. While the levels in the LE group $\left(0.71 \mu \mathrm{g} / \mathrm{m}^{3} /\right.$ day $)$ were within the guidelines. This finding alerted mine management to the risk to the human population in the area and action was taken to reduce these levels. It also supports the predicted NOAEL.

The inhalation component of the model allows comparison of the outputs of this model with plume-dispersion models to ensure its validity and can be used as an alternative to plume-dispersion modelling to assess the risk of exposure to the human population.

Little has been published on the EDTA soluble fraction of vanadium in soils. Publications usually refer to total vanadium in soil, because this is the easiest to determine. However, only a small fraction of the total vanadium is soluble $(0.8 \%$ LE pastures and $1.5 \%$ HE pastures), the rest is tightly bound and therefore probably not readily available for absorption by ruminants ingesting soil. The question of different fractions of vanadium and other minerals in exposure studies needs to be investigated more thoroughly. In this study the total vanadium concentrations in soil were consistently higher in the LE pastures (median $=622 \mathrm{mg} / \mathrm{kg}$ ) than the HE pastures (median $=392 \mathrm{mg} / \mathrm{kg}$ ), yet the soluble fractions reflected the inverse. This was expected because most of the fall-out occurred on the HE pastures, but it highlights the danger of simplifying metal-exposure assessments to just looking at total concentrations of a particular metal. Coupled to this is the potential confounder of the different vanadium compounds that are released and which occur in the environment. These factors emphasise the importance of hazard identification and release assessment when doing a sentinel study. Unlike in experimental studies, cattle in the field are exposed to a mixture of vanadium compounds of varying solubility and toxicity (Gummow, 2005). Yet modellers using stack emissions as a measure of exposure rarely differentiate between the different vanadium compounds. For example, the modellers doing Gaussian plume-dispersion models for this mining company based their model on the assumption that all emissions were $\mathrm{V}_{2} \mathrm{O}_{5}$, which was clearly not the case. 


\section{Conclusions}

Our exposure model provided a reasonable estimate of external exposure dose of vanadium for cattle grazing in the vicinity of a vanadium-processing plant and addressed the problem of variability in exposure characteristic of long-term field studies. It therefore provides an important tool necessary for further research into the consequences of exposure, assessment of biomarker responses, public-health implications and environmental impact studies.

\section{Acknowledgements}

We thank the following people for their various inputs into the project, Mr. J. Beukes, Professor C.J. Botha, Mr. L. Ford, Professor D.J.J. Heederik, Mr. P. Kruger, Professor J.P.T.M. Noordhuizen, Mr. D. Stein, Mr. J.J. van der Merwe and Ms. R. Watson.

\section{References}

Aldrich, T., Griffith, J., Cookie, C., 1993. Environmental Epidemiology and Risk Assessment. Van Nostrand Reinhold, New York.

Barth, A., Schaffer, A.W., Konnaris, C., Blauensteiner, R., Winker, R., Osterode, W., Rudiger, H.W., 2002. Neurobehavioral effects of vanadium. J. Toxicol. Environ. Health Part A 65 (9), 677-683.

Burger, L.W., Watson, R.M., 2003. Air quality impact assessment for Xstrata Rhovan vanadium smelter. Report No. EMS/03/XST-01 Rev 2. Environmental Management Services cc, Wierda Park, South Africa.

Clarkson, T.W., Weiss, B., Cox, C., 1983. Public health consequences of heavy metals in dump sites. Environ. Health Perspect. 48, 113-127.

CRC Handbook of Chemistry and Physics, 1977. CRC Press, Cleveland, OH.

EPA, 1995a. Compilation of Air Pollution Emission Factors (AP-42), fifth ed., vol. 1. US Environmental Protection Agency, Research Triangle Park, NC (as contained in the AirCHIEF (Air Clearing house for Inventories and Emission Factors) CD-ROM).

EPA, 1995b. Background Document to AP-42 Document, sixth ed., vol. 1. US Environmental Protection Agency, Research Triangle Park, NC (as contained in the AirCHIEF (Air Clearing house for Inventories and Emission Factors) CD-ROM).

Faulkner Hudson, T.G., 1964. Vanadium: Toxicology and Biological Significance. Elsevier Publishing Company, London.

Fox, M.R.S., 1987. Assessment of cadmium, lead and vanadium status of large animals related to the human food chain. Rev. J. Anim. Sci. 65 (6), 1744-1752.

Frank, A., Kristiansson, L., Petersson, F.K., 1992. Vanadinförgiftning hos nötkreatur-Första kända fallet i Sverige. Svensk Veterinartidning 42, 447-451.

Frank, A., Madej, A., Galgan, V., Petersson, L.R., 1996. Vanadium poisoning of cattle with basic slag. Concentrations in tissues from poisoned animals and from a reference, slaughterhouse material. Sci. Total Environ. 181, 73-92.

Friberg, L., Nordberg, G.F., Vouk, V.B. (Eds.), 1979. Handbook on the Toxicology of Metals. Elsevier/North Holland Biomedical Press, Amsterdam.

Gummow, B., Bastianello, S.S., Botha, C.J., Smith, H.J.C., Basson, A.J., Wells, B., 1994. Vanadium air pollution: a cause of malabsorption and immunosuppression in cattle, Onderstepoort. J. Vet. Res. 61, $303-316$. 
Gummow, B., Botha, C.J., Noordhuizen, J.P.T.M., Heesterbeek, J.A.P., 2005. The public health implications of farming cattle in areas with high background concentrations of vanadium. Prev. Vet. Medicine 72, 281-290.

Gummow, B., 2005. Vanadium mining and cattle health. Sentinel studies, epidemiological and veterinary public health issues. Ph.D. thesis. University of Utrecht, Utrecht, Netherlands.

Gummow, B., van den Broek, J., Kirsten, W.F.A., Botha, C.J., Noordhuizen, J.P.T.M., Heesterbeek, J.A.P., 2006. The assessment of biomarkers in sentinel cattle for monitoring vanadium exposure. J. Environ. Monit. 8, 445455.

Handbook of Standard Soil Testing Methods for Advisory Purposes, 1990. Soil Science Society of South Africa, P.O. Box 30030, Sunnyside 0132, Pretoria, Republic of South Africa.

Heath, C.W., 1983. Field epidemiological studies of populations exposed to waste dumps. Environ. Health Perspect. 48, 3-7.

Healy, W.B., 1968. Ingestion of soil by dairy cows. N. Z. J. Agric. Res. 11, 487-499.

Healy, W.B., 1970. In: Proceedings of the New Zealand Society of Animal Production, vol. 30. p. 11.

Hilliard, H.E., 1992. Vanadium. In: Bureau of Mines Minerals Yearbook, U.S. Department of the Interior, Washington, DC (in Nriagu (1998)).

La Manna, A.F., Owens, F.N., Janloo, S., Shenkoru, T., Welty, S.D., 1999. Impact of dietry salt concentration on water intake and physiological measurements of feedlot cattle. Animal Science Research Report, Department of Animal Science, Ohio State University, OH, USA.

McCrindle, C.M.E., Mokantla, E., Duncan, N., 2001. Peracute vanadium toxicity in cattle grazing near a vanadium mine. J. Environ. Monit. 3 (6), 580-582.

Murry, N., MacDiarmid, S.C., Wooldridge, M., Gummow, B., Morley, R.S., Weber, S.E., Giovannini, A., Wilson, D., 2004. Handbook on Import Risk Analysis for Animals and Animal Products, vols. 1 and 2. OIE (World Organisation for Animal Health), Paris, France.

Nriagu, J.O., 1998. Vanadium in the Environment. John Wiley \& Sons, Inc., New York.

Perera, F.P., Weinstein, I.B., 1982. Molecular epidemiology and carcinogen DNA adduct detection: new approaches to studies of human cancer causation. J. Chronic Dis. 35, 581-600.

Platonow, N., Abbey, H.K., 1968. Toxicity of vanadium to calves. Vet. Rec. 292-293.

Puls, R., 1989. Mineral levels in animal health. In: Diagnostic Data, Sherpa International, Clearbrook, BC, Canada.

Reece, W.O., 1991. Physiology of Domestic Animals. Lea \& Febriger, Philadelphia.

Reilly, C., 1991. Metal Contamination of Food, second ed. Elsevier Applied Science, New York.

Schroeder, H.A., Balassa, J.J., 1967. Arsenic, germanium, tin and vanadium in mice: effects on growth, survival and tissue levels. J. Nutr. 92, 245-252 (in Toxicological Profile for Vanadium (1992)).

Schroeder, J.A., Mitchener, M., Nason, A.P., 1970. Zirconium, niobium, antimony, vanadium and lead in rats: life term studies. J. Nutr. 100, 59-68 (in Toxicological Profile for Vanadium (1992)).

Schroeder, H.A., Mitchener, M., 1975. Life-time effects of mercury, methyl mercury, and nine other trace metals on mice. J. Nutr. 105, 452-458 (in Toxicological Profile for Vanadium (1992)).

Scott, H.M., Sodkolne, C.L., Martin, S.W., Ellehoj, E.A., Coppock, R.W., Guidotti, T.L., Lissemore, K.D., 2003 a Comparison of two atmospheric-dispersion models to assess farm-site exposure to sour-gas processing emissions. Prev. Vet. Med. 57, 15-34.

Scott, H.M., Sodkolne, C.L., Martin, S.W., Basarab, J.A., Coppock, R.W., Guidotti, T.L., Lissemore, K.D., 2003 b. Lack of associations between air emissions from sour-gas processing plants and beef cow-calf herd health and productivity in Alberta, Canada. Prev. Vet. Med. 57, 35-68.

Smith, B.P., 1990. Large Animal Internal Medicine. In: Diseases of Horses, Cattle, Sheep and Goats, The C.V. Mosby Company, Philadelphia.

Strass Environmental Science Engineering, 1998. Soil and plant material sampling and analysis. In: Ba-Mogopa Vanadium Mine, Strass Environmental, Noordwyk, South Africa.

Svendsen, P., Carter, A.M., 1984. An Introduction to Animal Physiology, second ed. MTP Press Ltd., Lancaster, England.

ter Heege, J., 1964. Een intoxicatie bij runderen door opname van stookoeroet. Tijdschr. diergeneesk. 89, 13001304 (in Frank et al. (1996)).

Thornton, I., Abrahams, P., September 1981. Heavy metals in the environmentIn: International Conference, Amsterdam, pp. 267-272. 
Toxicological Profile for Vanadium, 1992. US Department of Health \& Human Services, Public Health Service, Agency for Toxic Substances and Disease Registry, TP-91/29.

USEPA Standard Methods, 1986. Environmental Protection Agency. Test methods for evaluating solid waste, physical/chemical methods (SW-846): Method 3050, Acid digestion of sediments, sludges and soils. USA Environmental Protection Agency, Washington, DC.

USEPA Standard Methods, 1996. Environmental Protection Agency. Test methods for evaluating solid waste, physical/chemical methods: Method 3052, Microwave assisted acid digestion of siliceous and organically based matrices. USA Environmental Protection Agency, Washington, DC.

Vose, D., 2000. Risk analysis. In: A Quantitative Guide, John Wiley \& Sons, Ltd., Chichester, UK.

Whelan, P.M., Hodgson, M.J., 1979. Essential Principles of Physics. John Murray, Albemarie Street, London. WHO, 1987. Air Quality Guidelines for Europe. World Health Organisation, Regional Office of Europe, Copenhagen, Denmark (Europe Series No. 23).

Waters, M.D., 1977. Toxicology of vanadium. Adv. Mod. Toxicol. 2, 147-189. 